\title{
Improving the Methodological Tools of Market Pricing in Exhibition Marketing
}

\author{
Submitted $14 / 2 / 19,1^{\text {st }}$ revision $18 / 2 / 19,2^{\text {nd }}$ revision $20 / 2 / 19$, accepted $23 / 2 / 19$ \\ Ulanovskaya O.N., ${ }^{1}$ Osovtsev V.A., ${ }^{2}$ Larionov V.A., ${ }^{3}$ Badadyan L.V. ${ }^{4}$
}

\begin{abstract}
:
Purpose: The purpose of the study is to determine ways to improve the methodological pricing tools in exhibition marketing from market positions.

Design/Methodology/Approach: The leading method of research is a systematic approach, which is used to substantiate the economic and mathematical model of the optimal market price of the exhibition area, which is set depending on the quality of the exhibition. In order to measure differences in the quality of exhibition events, authors proposed to use referenceexhibition benchmarking characterized by the best price / quality ratio.

Findings: The results of the study form the methodological basis for improving pricing not only in the exhibition business, but also in other areas of business activity. This is possible if the goods (services) are produced in the conditions of a monopolistic competition, and the quality of an individual product (service) could be quantified in a conventional unit, which should be scientifically substantiated.

Practical implications: This study is of practical value for both exhibition organizers and their participants. Using of expo-activities of the developed methodological tools of market pricing allows strengthening their competitive positions and increasing the profitability of exhibitions, if the optimal market price of the exposition calculated by the proposed method compensates the average total costs of the exhibition company.

Originality/Value: The article substantiates the original conceptual approach to exhibition pricing, which is based on interaction marketing, benchmarking and extremely high price, which prevents the formation of demand from exhibitors, that is proposed to be called the alternative price. It becomes possible to provide a scientific basis for determining the optimal market price of the exhibition area, that maximizes the profit of the organizing company.
\end{abstract}

\footnotetext{
${ }^{1}$ Lecturer, Department of Marketing, Trade and Customs, V.I. Vernadsky Crimean Federal University, Simferopol, Russian Federation,agalakova.ok@gmail.com

${ }^{2}$ D.Sc. in Economics, Professor, Department of Marketing and Advertisment, Rostov State University of Economics, Rostov-on-Don, Russian Federation, osovtsevj@mail.ru

${ }^{3}$ Applicant, Department of Marketing and Advertising, Rostov State University of Economics, Rostov-on-Don, Russian Federation, OET2004@yandex.ru

${ }^{4}$ Applicant, Department of Marketing and Advertising, Rostov State University of Economics, Rostov-on-Don, Russian Federation.
} 
Keywords: Optimal price of the exhibition area, alternaive price, benchmarking, exhibition standard, integral quality indicator.

JEL Code: M31.

Paper type: Research paper.

\section{Introduction}

The price of the exhibition area is one of the exhibition marketing elements. The organizing company leases the area to the expo-participant. Exhibition pricing is currently characterized by a variety of approaches and often does not have a reasoned pricing policy. As practice shows, the definition of the "correct price" of the exhibition area is a rather complicated task (INFORMEXPO, 2010). The main exhibition services often tend to be insufficiently developed if priced in terms of compliance with the economic laws of the market. Exhibition pricing is mainly costoriented, there is no flexible price response to changing market conditions, and the peculiarities of current demand and competition in the market of expo services are not fully taken into account.

Such errors in exhibition pricing are explained by the insufficiently elaborated issues of scientific substantiation and the effective use of methodological tools of market pricing in exhibition marketing. At the same time, the market pricing method, according to the authors, is better than the cost approach to take into account the interests of the client (exhibition participant) and the organizer of the measures, and thus contributes to the development of interaction between them, and also allows increasing the competitiveness of the company - organizer. Hence, the improvement of exhibition pricing from the standpoint of its compliance with the laws of a market economy seems to be quite relevant.

The purpose of the study is to develop the methodological tools for market pricing in exhibition marketing, based on a systematic approach. The subject of the study is the economic relations arising in the field of exhibition activities between the expoorganizing companies and their participants regarding the main exhibition services provided by the organizers in the form of renting the area to exhibitors.

The working hypothesis of the study lies in the assumption that when improving the methodological tools of exhibition pricing, it is advisable to use the concept of extremely high prices that hinder the formation of exhibitors' demand for participation in an exhibition event, which is called the "price alternative" by the authors. 
The scientific novelty of the research lies in the development of theoretical and methodological aspects of market pricing in exhibition marketing, based on benchmarking, interaction marketing and the concept of "alternative price", which allows presenting the methodological tools of exhibition pricing in the form of an economic-mathematical model of the organizer, market price of the main exhibition services.

\section{Methodology of study}

The leading approach in the development of methodological tools for pricing in exhibition marketing is a systematic approach based on mathematical modeling of economic reality. Utilizing the systematic method, the authors substantiated the economic-mathematical model of the optimal market price of the expo area, which makes possible to comprehensively review and present the market approach to exhibition pricing in the form of analytical dependencies and graphs. The key parameter of the proposed economic and mathematical model is the extremely high price of exhibition area, which prevents the exhibitors' demand for participation in the exhibition, called by the authors the "alternative price" (Ulanovskaya, 2016).

The degree of reliability of the research results is ensured by the correct use of scientific works of domestic and foreign scientists, statistical data of the Russian Union of Exhibitions and Fairs (UEFEXPO, 2019), the Global Association of the Exhibition Industry (UFI.ORG, 2015). Reliability of the optimal (profit-maximizing) market price, based on the economic-mathematical model of the exhibition area, is ensured by utilizing algebraic and geometric research methods, including the standard method for studying functions for extremum.

In addition to the systematic approach, the following research methods were utilized: observation and collection of facts, statistical method, method of limit values, analytical, tabular and graphical.

\section{Results}

Methodical tools of pricing is a set of techniques and methods for determining (calculating) the price of a product or service.

In the field of expobusiness, the method for determining the exhibitors' demand for participation in a particular exhibition event has not yet been developed. Difficulties arise due to the fact that in the field of exhibition activities, specialized surveying is carried out once a year, and sometimes even less often: one event every two to three years or more. In such a situation, it is almost impossible to experiment with prices for exhibition area or use price data from previous periods to determine the price elasticity of exhibitors' demand in order to apply a market approach to exhibition pricing. At the same time, as Kotler (1990) noted, any method of calculation that does not take into account the peculiarities of current demand and competition is 
unlikely to allow reaching the optimal price (Kotler, 1990).

The initial conditions underlying the proposed economic-mathematical model of the optimal market price of the exhibition area are as follows. As a primary prerequisite, the standpoint is that exhibition activities are carried out in the conditions of a monopolistic competition market. In the short run, exhibition organizers act like monopolies.

The market aspects of monopolization as well as the pricing mechanism and the realization of monopoly profits under conditions of imperfect (essentially monopolistic) competition are thoroughly studied in the classic work of J. Robinson "Economic theory of imperfect competition" (Robinson, 1986). The study of monopoly in this book is based on the marginal analysis approach.

The essence of geometrical analysis by J. Robinson, which allows maximizing profits, is as follows: graphically, at the point of equality of marginal revenue and marginal costs, the monopolist's net income reaches the highest value and an equilibrium is observed, i.e., the condition when the increase or decrease in production leads to the decrease in net income (Robinson, 1986).

The profit maximizing price in the economic literature is called the optimal price (Shvets, 2013).

To implement the procedure of equalization of marginal revenue and marginal costs in order to achieve the highest value of total profit, the monopolist needs to determine the demand curve.

To study the conditions of sale (the demand) J. Robinson utilized a method based on the function of one independent variable, and a straight line as an analytical tool for studying supply and demand (Robinson, 1986).

Based on the method of J. Robinson, the authors used the linear function of one independent variable as an analytical tool for exponents' demand for exhibitors for the exhibition area of a particular expo-organizer:

$$
\mathrm{Q}=\mathrm{a}-\mathrm{b} \cdot \mathrm{P}
$$

where:

$\mathrm{P}$ is an independent variable in the form of the initial price of the expo area offered by a particular organizing company to exhibitors on the subject, rubles $/ \mathrm{m}^{2}$;

$\mathrm{Q}$ is the demand for the exhibition area of this organizing company from the exhibitors at various levels of the initial price $(\mathrm{P}), \mathrm{m}^{2}$;

a is the absolute term (equation 1), which, according to the authors, refers to the size 
of the expo area actually rented by the exhibitors at the last exhibition on the analyzed subject held by this organizing company, $\mathrm{m}^{2}$;

b - the slope term, or the coefficient of price elasticity of demand, expressed in absolute units $(\mathrm{b}=\Delta \mathrm{Q} / \Delta \mathrm{P}=\operatorname{ctg} \beta)$, which determines the slope or flatness of the demand line and the nature of its inelasticity or elasticity in general, $\left(\mathrm{m}^{2}\right) /$ (rub / $\left.\mathrm{m}^{2}\right)$.

Figure 1. Graph of the linear function of the exhibitors' demand for the exhibition area of a specific expo organizing company $(Q=a-b \cdot P)$

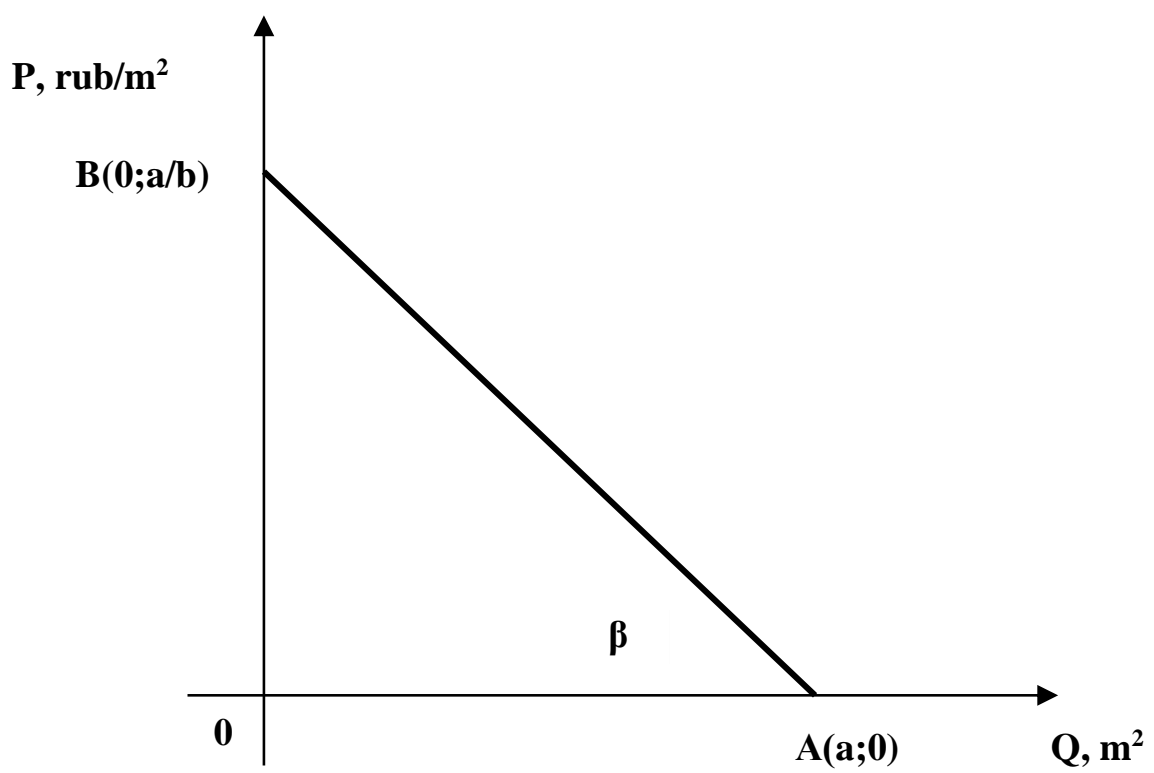

The coordinates of the two points are: A (a; 0$)$ and B (0; a / b) (Figure 1), which are characterized by extremely low $(\mathrm{P}=0)$ and extremely high $(\mathrm{P}=\mathrm{a} / \mathrm{b})$ price, respectively, were taken as the basis in the development of an economicmathematical model of the optimal market price of the exhibition area. Knowing the demand schedule, the estimated amount of costs and the price of competitors, the company is ready to choose the price of its own goods. This price will be in the range between too low, not providing profit, and too high, preventing the formation of demand (Kotler, 1990).

In the process of algebraic transformations of equation 1, the authors obtained the following equation for the linear demand function: 


$$
Q=a\left(1-\frac{P}{P_{\text {alt }}}\right)
$$

In this equation of the demand of exhibitors to participate in the exhibition event the parameter of price alternatives $\left(\mathrm{P}_{\text {alt }}=\mathrm{a} / \mathrm{b}, \mathrm{rub} / \mathrm{m}^{2}\right)$ was introduced by Ulanovskaya (2016). Actually, this is too high price that impedes the formation of demand (Kotler, 1990). The price of the alternative $\left(\mathrm{P}_{\text {alt }}=\mathrm{a} / \mathrm{b}\right)$, as applied to the expobusiness, quantitatively represents the upper limit of the independent variable in the form of the price of the exhibition area $(\mathrm{P})$ at which the value of expo-oganizers demand for it becomes equal to zero $(\mathrm{Q}=0)$.

The economic essence of the alternative price (Palt) in relation to the expo-business, according to the authors, is the price at which a zero value of exhibitors' demand is set to participate in this expo event due to the possibility of participation at the same price in an alternative event characterized by higher quality. Hence, the prices of competitors offering higher-quality expo services are a limiting factor in the way of increase in the price of exhibition area by other organizers.

Using the standard extremum test method of studying the function of total income $\mathrm{TR}=\mathrm{Q} * \mathrm{P}$ with respect to variable $(\mathrm{Q})$, the authors gave a rationale for the formula for establishing the optimal $\left(\mathrm{P}_{\mathrm{Opt}}\right)$, that is, maximizing the total profit of the organizing company, the market price of the exhibition area (Ulanovskaya, 2016):

$$
P_{\text {Opt }}=0,5 \times\left(P_{\text {alt }}+M C\right),
$$

where:

$\mathrm{P}_{\mathrm{Opt}}$ is the optimal price of the exhibition area $\left(\right.$ rubles $/ \mathrm{m}^{2}$ ), maximizing the total profit of the expo-organizing company, which is possible if $\mathrm{P}_{\mathrm{Opt}}$ is greater than the average total cost ( $\left.\mathrm{P}_{\mathrm{opt}}>\mathrm{ATC}\right)$ and marginal revenue (MR) is equal to marginal cost (MC). Marginal costs (MC) of the organizing company are associated with the opening, holding and completion of the exhibition, RUB $/ \mathrm{m}^{2}$.

For the practical application of equation 3, the key issue is the method for determining the value of the alternative price $\left(\mathrm{P}_{\text {alt }}\right)$. To substantiate it, the authors considered the process of establishing the optimal market price for an exhibition area in case when $M R=M C=0$ shown in Figure 2 (point $C$ ). Such an identity MR $=\mathrm{MC}=0$ takes place in practice, in case of compensation by the organizers of the marginal costs (MC) of the measures by charging the obligatory registration fee from the exhibitors. This approach is widely practiced by many expo-organizers. At point $\mathrm{F}$, which lies exactly in the middle of the demand line $\mathrm{Q}=\mathrm{a}-\mathrm{b} \cdot \mathrm{P}$ (segment $\mathrm{JK}$, Figure 2), the price elasticity is equal to one, which ensures the maximization of the total income and profit of the organizing company expo-events at the optimum price corresponding to this point $\mathrm{F}\left(\mathrm{P}_{\mathrm{opt}}\right)$. 
Figure 2. Graphic representation of the process of determining the optimal market price of the expo area in case when $M R=M C=0$ (developed by authors on the basis of Robinson, 1986)

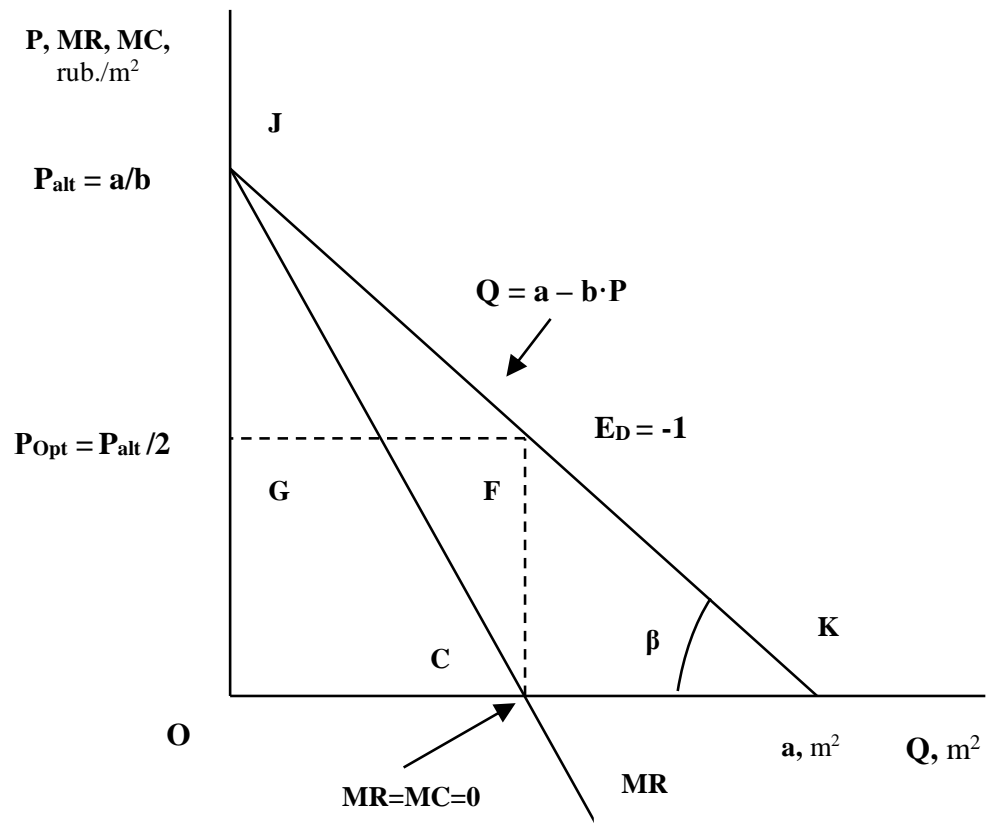

In case when $\mathrm{MR}=\mathrm{MC}=0$, the analytical dependence (equation 3) takes the following form:

$$
P_{\text {Opt }}=0,5 \cdot P_{\text {alt }}
$$

The quantitative properties of exhibitions and fairs like number of visitors and exhibitors, the size of the exhibition area rented are also indicators of the quality of these events (Simonov, 2014). To determine the price of the exhibition area adequate to the quality of the expo events, the authors attempted to substantiate its corresponding integral indicator. To achieve this goal, authors processed a vast amount of data on specialized trade shows in the leading sector of the economy such as "Engineering, industry, manufacturing, machinery, tools, equipment" (UFI code). This source of information included official statistics on 67 international B2B exhibitions held in 2015 in Russia, Germany, Italy and France (UFI.ORG, 2015).

Statistical information characterizing the quality of the experiments was subjected to correlation analysis. Table 1 presents the results. A comparison of the calculated value of the correlation coefficient ( $\mathrm{r}$ ) with the tabular (critical) value ( $\mathrm{r}$ crit) taking into account the number of correlated pairs and the chosen level of significance $(\mathrm{p}<$ 0.05) shows that since ( $r>r$ crit), the null hypothesis is rejected. Based on this, 
authors consider that the random variables are correlated, that is, having a linear subjection.

Table 1 makes clear that the calculated correlation coefficients are close to one. This indicates a high degree of interconnection between the studied pairs of random variables characterizing the quality of the exhibition. The statistical pattern established by the example of exhibitions organized in the engineering industry is inherent, as shown by authors, to exhibition events in other industry sectors of the economy.

Table 1. Evaluation of the closeness of the relationship (in pairs) between the number of visitors, exhibitors and the size of the rented exhibition area (developed by authors on the basis of UFI.ORG, 2015

\begin{tabular}{|c|c|c|c|}
\hline \multirow{4}{*}{$\begin{array}{c}\text { The size of the } \\
\text { exhibition area, } \mathrm{m}^{2}\end{array}$} & $\begin{array}{c}\text { The size of the } \\
\text { exhibition area, } \mathrm{m}^{2}\end{array}$ & $\begin{array}{c}\text { Number of } \\
\text { exhibitors, legal } \\
\text { entities and } \\
\text { individuals }\end{array}$ & $\begin{array}{c}\text { Number of visitors, } \\
\text { person per day }\end{array}$ \\
\cline { 2 - 4 } & Gussia & 0,940708 & 0,791019 \\
\cline { 2 - 4 } & Italy & 0,801933 & 0,800505 \\
\hline \multirow{2}{*}{$\begin{array}{c}\text { Number of } \\
\text { exhibitors, legal } \\
\text { entities and } \\
\text { individuals }\end{array}$} & 0,940708 & 0,974933 & 0,924038 \\
\cline { 2 - 4 } & 0,801933 & 0,917974 & 0,969832 \\
\cline { 2 - 4 } & 0,974933 & Russia & 0,876761 \\
\hline \multirow{2}{*}{$\begin{array}{c}\text { Number of visitors, } \\
\text { person per day }\end{array}$} & 0,917974 & Italy & 0,614455 \\
\cline { 2 - 4 } & 0,791019 & 0,876761 & 0,859283 \\
\cline { 2 - 4 } & 0,800505 & 0,614455 & Russia \\
\cline { 2 - 4 } & 0,924038 & 0,859283 & Germany \\
\hline
\end{tabular}

The study concluded that the number of exhibitors, the number of visitors, and the total size of the exhibition area rented by the participants could be used as a generalized (integral) indicator of the quality of the expo events. Since, in practice, the contract for participation in an exhibition and fair event is based on the rent of exhibitors of the exhibition area, and not on the number of visitors or participants of the event, giving the authors the basis for considering the size of the exhibition area rented by exhibitors as an integral indicator characterizing the activity. Such an approach to the study allows carrying out quite simply (if relevant information is available) calculations of the relative value for money. 
To determine the expression of the relative price / quality value, the original linear demand function of exhibitors (equation 1) was converted to its inverse function:

$$
P=P_{a l t}-K \cdot Q
$$

where $(\mathrm{K}=1 / \mathrm{b})$ is the angular coefficient, which is a parameter that quantitatively expresses the "price / quality" ratio and has the following dimensionality (rubles / $\left.\mathrm{m}^{2}\right) /\left(\mathrm{m}^{2}\right)$. By transforming the expression $(\mathrm{K}=1 / \mathrm{b})$, the following formula was determined:

$$
\mathrm{K}=\mathrm{P}_{a l l} / \mathrm{a}
$$

Equation 6 allows calculating the relative price / quality ratio for each exhibition, if the value of the alternative price $\left(\mathrm{P}_{\text {alt }}\right)$ is known.

In order to establish the optimal market price of the exhibition area $\left(\mathrm{P}_{\mathrm{opt}}\right)$ depending on the quality of the conducted surveying, a certain reference point is needed. Guided by the principles of benchmarking, authors believe that such a "point" (base for comparison) should be one of the largest in scale and best in price / quality ratio exhibition of the relevant topical focus in the market segment of the exhibition services, which the authors propose to call the reference exhibition (Osovtsev and Ulanovskaya, 2017). The reference exhibition refers to A.

Using equations (3), (4) and (6) and their arithmetic conversions, authors determined the expression of the optimal (profit-maximizing) market price of the net exhibition area (equation 7), which is established depending on the price / quality ratio at the A reference exhibition (Osovtsev and Ulanovskaya, 2017):

$$
P_{o p t}=\frac{a}{A} P_{o p t}^{A}
$$

where:

$P_{o p t}^{A}$ is the optimal expo area price for the A reference exposition, rub / $\mathrm{m}^{2}$;

$P_{o p t}^{A}$ refers to the current market price of the net exhibition area prevailing at the reference exhibition, which was formed in the course of competition with domestic and foreign organizers of similar events in the market under the supply and demand forces;

$A$ is the dimensions of the A reference exhibition measured by the exhibition area (net) actually leased by the exhibitors at the last (to date) experiment, $\mathrm{m}^{2}$. This is an integral indicator of the quality of the A reference exhibition, which has a dimension $\left(\mathrm{m}^{2}\right)$; 
$a$ is the size of the exhibition area rented by the exhibitors of the specific companyorganizer at the last experiment, $\mathrm{m}^{2}$. This is an integral indicator of the quality of this exhibition, which has a dimension $\left(\mathrm{m}^{2}\right)$.

Thus, the analytical relationship (equation 7) is a key and final element of the proposed economic and mathematical model of the optimal market price for the net exhibition area.

\section{Discussion}

The practical implementation by expo-organizers of analytical dependence (equation 7) is connected with the following algorithm recommended by the authors. It is illustrated by the example of the Dominanta advertising and exhibition company (Simferopol) (DOMINANTA-EXPO.COM, 2019), operating in Crimea from 2001 to the present.

For example, the management of Dominanta has decided to conduct a Leather Footwear - Fur expo event for a period of 3 days. This topic of the exhibition corresponds to the branch code "B.05. Textiles, clothing, shoes, leather". The net area for the future exhibition is $\left(\mathrm{a}=620 \mathrm{~m}^{2}\right)$. And according to the forecast, it will be fully demanded by the exhibitors.

Based on a study of the statistical information of the Russian Union of Exhibitions and Fairs on the best audited exhibitions, the reference exhibition on the topics as of 2017 is the International Fair "Leather - Footwear - Fur - Technology" (UEFEXPO, 2018; LEGPROMEXPO, 2019). In fact, the exhibition area leased by the exhibitors, together with special expositions, in 2016 came to $\mathrm{A}=2210 \mathrm{~m}^{2}$, and its duration was 4 days (UEFEXPO, 2016). The website of the expo discloses the information about the price of $1 \mathrm{~m}^{2}$ standard-equipped exhibition area (net) for Russian enterprises (domestic exhibitors) for 2018, which is $P_{o p t}^{A}=12000$ rubles $/ \mathrm{m}^{2}$ for 4 days of the exhibition (LEGPROMEXPO, 2019). The adjusted price for 3 days of the exhibition for Dominanta is: $P_{o p t}^{A}=12000 \times 3 / 4=9000$ rubles $/ \mathrm{m}^{2}$. The cost of net exhibition area at the "Leather - Footwear - Fur" exhibition organized by the Dominanta company amounts to: ATC $=4421$ rubles $/ \mathrm{m}^{2}$. Thus, there is all the necessary information for calculating the market price of the net expo area of Dominanta according to equation 7 in rub $/ \mathrm{m}^{2}$ as follows:

$$
P_{O p t}=\frac{a}{A} P_{O p t}^{A}=\frac{620}{2210} * 9000=2525
$$

With this price and current costs $4421 \mathrm{rub} / \mathrm{m}^{2}$, Dominanta will incur losses in the amount of $P_{r}=\left(P_{o p t}-A T C\right)=2525-4421=-1896$ rubles $/ \mathrm{m}^{2}$. It is due to the high costs that the company has to apply the cost method and set the price of its exhibition area at the level of 6,000 rubles per square meter which is higher than the 
$\mathrm{P}_{\mathrm{Opt}}=2525 \mathrm{rub} / \mathrm{m}^{2}$ calculated by the proposed method and more than 2 times and even higher than the alternative price $\mathrm{P}_{\text {alt }}=5050$ rubles $/ \mathrm{m}^{2}$. This is graphically presented in Figure 3.

Figure 3. Graph illustrating the establishment of the market price of the exhibition area of Dominanta (Simferopol), depending on the pricelquality ratio at the $A$ reference exhibition (Moscow) (developed by authors)

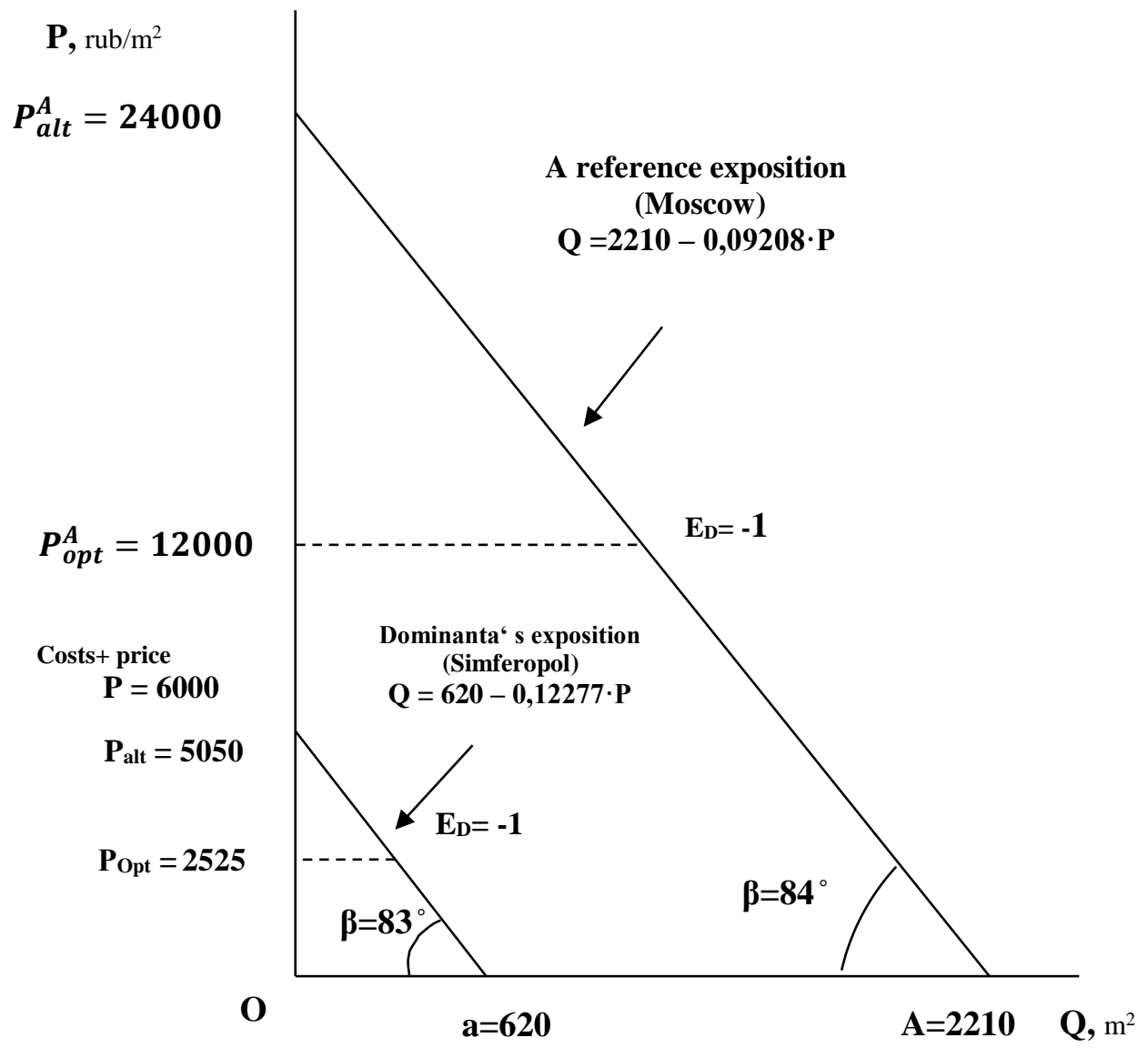

The proposed economic and mathematical model of the optimal market price of the exhibition area could be used by those expo-organizers whose price $\left(\mathrm{P}_{\mathrm{Opt}}\right)$ calculated on the basis of the application of the proposed market approach, not only reimburses the costs associated with preparing, opening, conducting and completing the event, but also provides a profit.

The strive of the organizer to set the price higher than the one calculated by the proposed market price method $\left(\mathrm{P}_{\mathrm{Opt}}\right)$ will inevitably lead to a deterioration in its price / quality ratio in comparison with the reference exhibition, and, consequently, 
to loss of competitiveness. This will likely happen if the exhibitors are not in a state of inertia or ignorance (unawareness), which prevent them from swapping one vendor of exhibition services for another, with the best price / quality ratio.

\section{Conclusion}

The economic and mathematical model of the optimal market price for expo area, which is based on the concept of alternative price, allows expo organizers to utilize the market approach in pricing, which is more consistent with the principles of exhibition marketing than the cost method.

To determine the optimal market price of the expo area depending on the quality of the exhibition, the authors propose to use benchmarking clarified using the integral price / quality indicator that is currently prevailing at the reference exhibition in the analyzed sector of the economy and the market segment of exhibition services.

The theoretical significance of the study is that its results can serve as a methodological basis for improving pricing in other areas of activity. This is possible if the goods (services) are produced in the conditions of the market of monopolistic competition, and the quality of an individual product (service) can be quantified in a conventional unit, which should be scientifically substantiated.

The practical significance of the study lies in the fact that using by expo-organizers of the methodological tools of market pricing proposed in the article will strengthen their competitive position and increase the profitability of exhibitions, if the optimal market price of the exposition calculated by the proposed method compensates for the average cost of the exhibition. This price is also beneficial for exhibitors, since it is set taking into account differences in the quality of exhibition events.

\section{References:}

DOMINANTA-EXPO.COM. 2019. Advertising and exhibition company Dominanta (Simferopol). The cost of participation in the exhibition on the topic "Beauty Industry", available online: http://www.dominanta-expo.com/index/industriyakrasoty/stoimost-uchastiya/

INFORMEXPO. 2010. Pricing strategy and pricing policy in the exhibition industry: Pricing strategy or "cheating the cost of the exhibition area" in 40 times? Third All-Russian Conference "Exhibition, Fair and Congress Activities and Modernization of the Russian Economy." THE EXPO REPORTER (2010), 3-4: 30-33, available online: http://www.informexpo.ru/just/uni/ExpoVed_3-4_09-10-2010_pg30-33.pdf

Kotler, F. 1990. Fundamentals of Marketing. Moscow, Progress, 736.

LEGPROMEXPO. 2019. Exhibition company LLC "RLP-Fair". The official site of LLC RLP-Fair, available online: http://www.legpromexpo.ru/exhibitors.html

Osovtsev, V.A., Ulanovskaya, O.N. 2017. Determining the price of the exhibition area, depending on the quality of the expo-events. Practical marketing, 10(248), 30-39.

Robinson, J. 1986. The economic theory of imperfect competition. Moscow, Progress, 472. 
Shvets, I.Y. 2013. Prerequisites for optimizing price forming and determining its free and regulated areas. Economics and Management, 4, 23-28.

Simonov, K.V. 2014. Modern Expo business: Business Conditions and Management Technologies. Moscow, INFRA-M, 656.

UEFEXPO. 2016. Statistical Review 2016: RUEF audited exhibitions. Available online: http://www.uefexpo.ru/data/objects/0007/2006/file.72006.stat_2016 en.pdf

UEFEXPO. 2018. Best exhibitions RUEF 2017/2018. Available online: http://www.uefexpo.ru/_data/objects/0005/4214/file.54214.ruef best_exhibitions 201 7-2018.pdf

UEFEXPO. 2019. Database of exhibitions. Official site of the Russian Union of Exhibitions and Fairs. Available online: http://www.uefexpo.ru/?id=227

UFI.ORG. 2015. Euro Fair Statistics 2015. Available online: http://www.ufi.org/wp- content / uploads / 2016/09 / 2015 euro fair_statistics_b.pdf

Ulanovskaya, O.N. 2016. Market approach to the creation of the optimal price for exhibitors to participate in regional exhibitions (fairs). Bulletin of the Rostov State University of Economics, 3(55), 67-72.

Ulanovskaya, O.N., Osovtsev, V.A. 2017. Methodical aspects of marketing price forming policy in the field of exhibition activity. RISC: Resources, Information, Supply, Competition, 1, 49-53. 